\title{
Unacceptable Failures: the Sixth Report of the Lancet Commission into Liver Disease in the UK
}

\author{
Authorship \\ Name \\ Professor Roger Williams \\ UK \\ Professor Guruprasad Aithal \\ Professor Graeme Alexander \\ Nottingham UK \\ Michael Allison \\ $\mathrm{PhD} \quad$ Liver Unit, Department of Medicine, Cambridge Biomedical \\ Research Centre, Cambridge University Hospitals NHS Foundation \\ Trust, UK \\ Iain Armstrong \\ Public Health England, UK \\ Richard Aspinall \\ PhD Portsmouth Hospitals NHS Trust, Portsmouth, UK \\ Professor Alastair Baker \\ Professor Rachel Batterham \\ Katrina Brown \\ Robyn Burton \\ Professor Matthew E Cramp \\ Natalie Day \\ Professor Anil Dhawan \\ Professor Colin Drummond \\ James Ferguson \\ Professor Graham Foster \\ Professor Sir Ian Gilmore \\ MD Liver Centre for Alcohol Research, University of Liverpool, UK \\ Jonny Greenberg \\ BA Incisive Health, London, UK \\ Clive Henn \\ Helen Jarvis \\ Professor Deirdre Kelly \\ Mead Mathews \\ Annie McCloud \\ Alastair MacGilchrist \\ MBA King's College Hospital, London, UK \\ $\mathrm{PhD}$ National Institute of Health Research, UCLH Biomedical Research \\ Centre, London, UK \\ PhD Cancer Intelligence Team, Cancer Research UK \\ $\mathrm{PhD} \quad$ Public Health England \\ MD Plymouth University Peninsula Schools of Medicine and Dentistry, \\ Plymouth, UK \\ MA Institute of Hepatology, London, Foundation for Liver Research, \\ UK \\ MD King's College Hospital, London, UK \\ MD Institute of Psychiatry, Psychology \& Neuroscience, King's College \\ London and South London and Maudsley NHS Foundation Trust \\ MD NIHR Birmingham Biomedical Research Centre at University \\ Hospitals Birmingham NHS Foundation Trust \\ FRCP Barts Liver Centre, Queen Mary University of London, London, \\ UK \\ RMN Public Health England \\ MBBS Newcastle University, UK and The Royal College of General \\ Practitioners, UK \\ MD Birmingham Women's and Children's Hospital, Birmingham, UK \\ MRCP St Mary's Surgery, Southampton, UK \\ MSc Kent \& Medway NHS and Social Care Partnership \\ FRCP Royal Infirmary of Edinburgh, Scotland
}




\begin{tabular}{|c|c|c|}
\hline Martin McKee & $\mathrm{DSc}$ & London School of Hygiene and Tropical Medicine, UK \\
\hline Kieran Moriarty & FRCP & British Society of Gastroenterology, UK \\
\hline Joanne Morling & $\mathrm{PhD}$ & $\begin{array}{l}\text { Division of Epidemiology and NIHR Nottingham Biomedical Research } \\
\text { Centre, Nottingham, University Hospitals NHS Trust and the University of } \\
\text { Nottingham, UK }\end{array}$ \\
\hline Professor Philip Newsome & le $\mathrm{PhD}$ & $\begin{array}{l}\text { National Institute for Health Research Biomedical Research Centre at } \\
\text { University Hospitals, Birmingham NHS Foundation Trust and the } \\
\text { University of Birmingham, UK }\end{array}$ \\
\hline Peter Rice & CPsych & Scottish Health Action on Alcohol Problems (SHAAP) \\
\hline Stephen Roberts & $\mathrm{PhD}$ & Swansea University Medical School, Wales \\
\hline Harry Rutter & BChir & University of Bath, Bath, UK \\
\hline Marianne Samyn & MD & King's College Hospital, London, UK \\
\hline Katherine Severi & $\mathrm{MSc}$ & Institute of Alcohol Studies, London, UK \\
\hline Professor Nick Sheron & MD & European Public Health Alliance, Brussels, Belgium \\
\hline Douglas Thorburn & MD & Royal Free Hospital, London, UK \\
\hline Julia Verne & $\mathrm{PhD}$ & Public Health England, UK \\
\hline Jyotsna Vohra & $\mathrm{PhD}$ & Cancer Policy Research Centre, Cancer Research UK \\
\hline John Williams & FRCP & Swansea University Medical School, Wales \\
\hline Andrew Yeoman & MD & Aneurin Bevan University Health Board, Newport, UK \\
\hline
\end{tabular}

Corresponding author:

Professor Roger Williams

Institute of Hepatology, Foundation for Liver Research

111 Coldharbour Lane

London SE5 9NT

r.williams@ researchinliver.org.uk

Telephone: 02072559830 


\section{Executive Summary}

This final report of the Lancet Commission into Liver Disease in the UK stresses the continuing increase in disease burden of liver disease from excess alcohol consumption and obesity, with high levels of hospital admissions and a worsening in deprived areas. It concludes that only with comprehensive food and alcohol strategies based on fiscal and regulatory measures including the Minimum Unit Price (MUP) for alcohol and the alcohol duty escalator, as well as an extension of the sugar levy on food content which has been proven by previous experience in this country, can the disease burden be curtailed. Further evidence of the value of MUP is shown by initial published results (1) of its introduction in Scotland showing an overall 3\% reduction in consumption, with the major effect as predicted on heavy drinkers of low-cost alcohol products The major contribution of obesity and alcohol to the high rates of the ten most common cancers is also discussed. The measures outlined by the departing Chief Medical Officer, Dame Sally Davies, to combat rising levels of obesity - the highest of any country in the West - are described along with the estimated health costs.

The latest audit analysis of unacceptable levels of mortality for severely ill patients with liver disease in District General Hospitals (DGHs)(2) indicates the need for developing a masterplan for improving hospital care and such a plan is proposed in this report based around specialist hospital centres linked to DGHs by Operational Delivery Networks (ODNs). It has received strong backing from the British Association for Study of the Liver (BASL) and British Society of Gastroenterology (BSG) but is held up at NHS England (NHSE). The value of day-case care bundles to reduce high hospital readmission rates with greater care in the community is described, along with examples of locally derived schemes for the early detection of disease and in particular schemes to allow general practitioners (GPs) to refer patients directly for elastography assessment. New funding arrangements for GPs will be required if these are to be taken up more widely around the country, as is recommended.

A new ComRes poll, to be published in autumn 2019, shows an appalling lack of understanding of harm to health from lifestyle causes, with a poor knowledge of alcohol consumption and dietary guidelines. The Commission has serious doubts as to whether the initiatives described in the Prevention Green Paper(3), with the onus placed on the individual based on the use of information technology and the latest in behavioural science will be effective. The final section of the report raises questions of meaningful survival in paediatric liver disease where despite excellent overall survival results, there are high levels of cognitive impairment.

In the Conclusion, a strong plea is made for greater coordination between the various official and non-official bodies that have expressed views on the unacceptable disease burden from liver disease in this country in presenting a single, strong voice to the higher echelons of Government. It is those making the final decisions and whom the Commission can only presume are not yet convinced of the need.

Not included in the report are the continuing efforts to eradicate hepatitis $\mathrm{C}$ virus (HCV) infection based on the extension of treatment by the new antiviral drugs to previously unidentified patient groups. Hepatitis B Virus (HBV) infection is also not considered as the efficacy of the new potentially curative agents remains to be established in multi-centre clinical trials.

\section{Introduction}

Although in last year's report we wrote optimistically of a gathering momentum and to some extent this has continued, this year's report is mainly concerned with a series of ongoing failures in terms of the continuing. harmful effects on health resulting from lifestyle causes. The broadcaster Adrian Chiles, who had learnt of the dangers of heavy drinking before it was too late for him personally, has been powerful in advocacy and was instrumental in the BBC Panorama programme in June, directed at the lobbying power of the drinks industry and its influence on Government policy. Sadly, the past 12 months have seen no progress in Government instituting the regulatory and fiscal measures which are the only proven way of controlling overall alcohol consumption in a country. In the Government's recently published Green Paper "Advancing Our Health: Prevention in the 2020 s"(3), although acknowledging the extraordinarily high levels of overweight and obesity in the population, the main concern appears to be in tackling childhood obesity and for adults with obesity, the main funding commitment was for diabetes. The UK has the highest rate of obesity of any major nation in Western Europe and the latest report by the OECD described the conditions fuelled by excess body weight as soaking up more than $8 \%$ of health expenditure in the UK while cutting life expectancy by an average of 2.7 years(4). 
Although NHSE has announced new funding for alcohol care teams in hospitals(5) with the highest levels of admissions due to alcohol dependency, with one in five patients in UK hospitals consuming alcohol at a harmful levels and one in ten alcohol dependant(3), many more hospitals will need to be included in the scheme.

Not surprisingly, with the continuing rise in hospital admissions of severely ill liver disease patients, adequate care and facilities continue to lag behind and the mortality figures can only be described as unacceptable. Further work this year has gone into developing a hospital masterplan based on networks of DGHs linked with specialist liver centres. But as indicated in this section of the report, the proposals are held up awaiting endorsement by NHSE. Results are given in the report on the use of transient elastography by groups of GPs in screening for early liver disease, showing it to be worthwhile in terms of detecting previously undiagnosed cirrhosis cases at a stage when treatment measures can be effective. The severe cuts in community alcohol and addiction services are likely to add to the difficulties here as a result of reductions in public health spending.

A worrying new finding relates to occurrence of neurocognitive impairment in infants and children with liver disease, raising issues over meaningful life outcomes. Also new to the Commission's work this year and described in detail is a ComRes poll on public awareness of liver disease. The one encouraging event in recent months was a National Institute for Health Research (NIHR) broad call for research projects of a translational nature in liver disease encompassing many of the recommendations that have been made by the Lancet Commission.

\section{Alarming Lack of Public Awareness: Results of the ComRes Poll}

Polling by ComRes between $24^{\text {th }}$ and $27^{\text {th }}$ May 2019 of 2,016 British adults aged $>18$ years, exposed a lack of knowledge about liver disease. Participants were asked a series of factual statements that assessed their knowledge of the causes of liver diseases and other elements of it. Questions were reviewed by ComRes consultants, who ensured validity of facts and balance in the questions.

Almost one third (32\%) of respondents wrongly believed the burden and number of deaths caused by liver disease in the UK are falling year-on-year. Only one in ten (11\%) can correctly identify all three main causes of liver disease, whilst a quarter (26\%) mistakenly think smoking is one of them.

$89 \%$ correctly identify drinking harmful levels of alcohol as part of the official drinking guidelines, but wrongly identified the weekly limit for men and women as over 14 units as advised by the UK Chief Medical Officers. In addition, $61 \%$ of respondents consider it possible to drink higher than recommended levels of alcohol for years without noticing any apparent harm to their health. 57\% of alcohol drinkers claim their current level of consumption has no impact on their health, whilst just a quarter (26\%) recognise it has a negative impact. Only $43 \%$ of respondents agreed that labels on alcoholic drinks currently contain enough information on the health risks for the public to make informed choices, emphasising the need for more accurate and comprehensive labelling of alcoholic beverages.

Two in five (40\%) British adults rightly identify obesity as one of the three main causes of liver disease which is lower than the level of knowledge about alcohol misuse as a key risk factor. To combat obesity, there is overwhelming public support for reducing the sugar content in foods $(77 \%)$ and making healthy food and drinks cheaper than unhealthier ones $(81 \%)$.

These findings, showing a lack of public appreciation of health information, should be viewed in the context of other similar reports. 
Figure 1: Summary of Key Findings of the ComRes survey

\begin{tabular}{|c|c|c|c|}
\hline \multicolumn{2}{|c|}{ BURDEN OF LIVER DISEASE } & \multicolumn{2}{|c|}{ MAIN CAUSES OF LIVER DISEASE } \\
\hline \multicolumn{2}{|c|}{$\begin{array}{l}\text { In the UK, the disease burden and deaths caused by liver } \\
\text { disease are falling year-on-year: }\end{array}$} & \multicolumn{2}{|c|}{$\begin{array}{l}\text { Which are the three main causes of liver disease?* } \\
\text { Alcohol misuse: } 89 \% \\
\text { Obesity: } 40 \% \\
\text { Viral hepatitis: } 35 \% \\
\text { All three above correctly selected: } 11 \% \\
\text { Smoking: } 26 \% \\
\text { *Based on prompted responses, including a range of other options } \\
\text { included in the survey (not listed: inherited genetic factors, blockages } \\
\text { to the gallbladder, lack of iron in the diet, sleep deprivation) }\end{array}$} \\
\hline \multicolumn{4}{|c|}{ MISCONCEPTIONS ABOUT ALCOHOL MISUSE } \\
\hline $\begin{array}{l}\text { "You can drink higher than recommended } \\
\text { levels of alcohol for years without } \\
\text { noticing any apparent harm to your } \\
\text { health": } \\
\text { True: } 61 \% \text { (N.B. correct answer) } \\
\text { False: } 39 \%\end{array}$ & \multicolumn{2}{|c|}{$\begin{array}{l}\text { Estimated number of units per week } \\
\text { as the official level for low-risk } \\
\text { drinking according to the UK Chief } \\
\text { Medical Officers' guidance: } \\
14 \text { units: } 16 \% \text { (N.B correct answer) } \\
\text { More than } 14 \text { units: } 13 \% \\
\text { Less than } 14 \text { units: } 39 \% \\
\text { Do not know: } 33 \%\end{array}$} & $\begin{array}{l}\text { How, if at all, do you consider your current level } \\
\text { of alcohol consumption to impact your health? } \\
\text { Of those who drink alcohol }(\mathrm{n}=1,660) \\
\text { No impact: } 57 \% \\
\text { Negative impact: } 26 \% \\
\text { Positive impact: } 14 \%\end{array}$ \\
\hline \multicolumn{4}{|c|}{ STEPS TO COMBAT ALCOHOL MISUSE AND OBESITY } \\
\hline $\begin{array}{l}\text { To what extent, if at all, do you support or } \\
\text { following measures aimed at reducing obe }\end{array}$ & $\begin{array}{l}\text { ppose each of the } \\
\text { y? }\end{array}$ & $\begin{array}{l}\text { To what extent, } \\
\text { following? } \\
\text { "Labels on alcoh } \\
\text { for the public to }\end{array}$ & $\begin{array}{l}\text { all, do you agree or disagree with each of the } \\
\text { drinks contain enough information on health risks } \\
\text { e informed choices" }\end{array}$ \\
\hline
\end{tabular}

ComRes interviewed 2016 British adults aged $>18$ yrs online between $24^{\text {th }}-27$ th May 2019. Data were weighted by key demographics including age, gender, region and social grade in order to be representative of all British adults. ComRes is a member of the British Polling Council and abides by its rules. Full data tables are available from https://www.comresglobal.com/polls/foundation-for-liver-research-public-polling/(published online 10.10.2019)

\section{Continuing High Alcohol Consumption and Disease Burden}

Data from the Office for National Statistics shows that in 2017, 57.0\% adults aged 16 years and over drank alcohol in the week before being interviewed which equates to 29.2 million people in the UK (Figure 2). The recent Monitoring and Evaluating Scotland's Alcohol Strategy (MESAS) report(6) on the effects of introduction of MUP (at 50pence per unit), showed a 3\% reduction in consumption in Scotland for 2018 against a 2\% overall increase in alcohol sales in England(1) and the recently published, sophisticated modelling exercise on the immediate impact of MUP showed a reduction in weekly purchases of $9.5 \mathrm{~g}$ of alcohol per gram of alcohol was associated with an increase in purchase price of $0.64 \%$ - higher in lower income households, targeting the heavy drinkers of cheap alcohol. The results of the first 12 months of MUP on disease severity and mortality are likely to be confirmatory and during the first 20 years the policy, it is estimated, will result in 2036 fewer deaths.

Figure 2: Self-reported drinking habits in the week prior to interview, Great Britain 2005-17(7) 


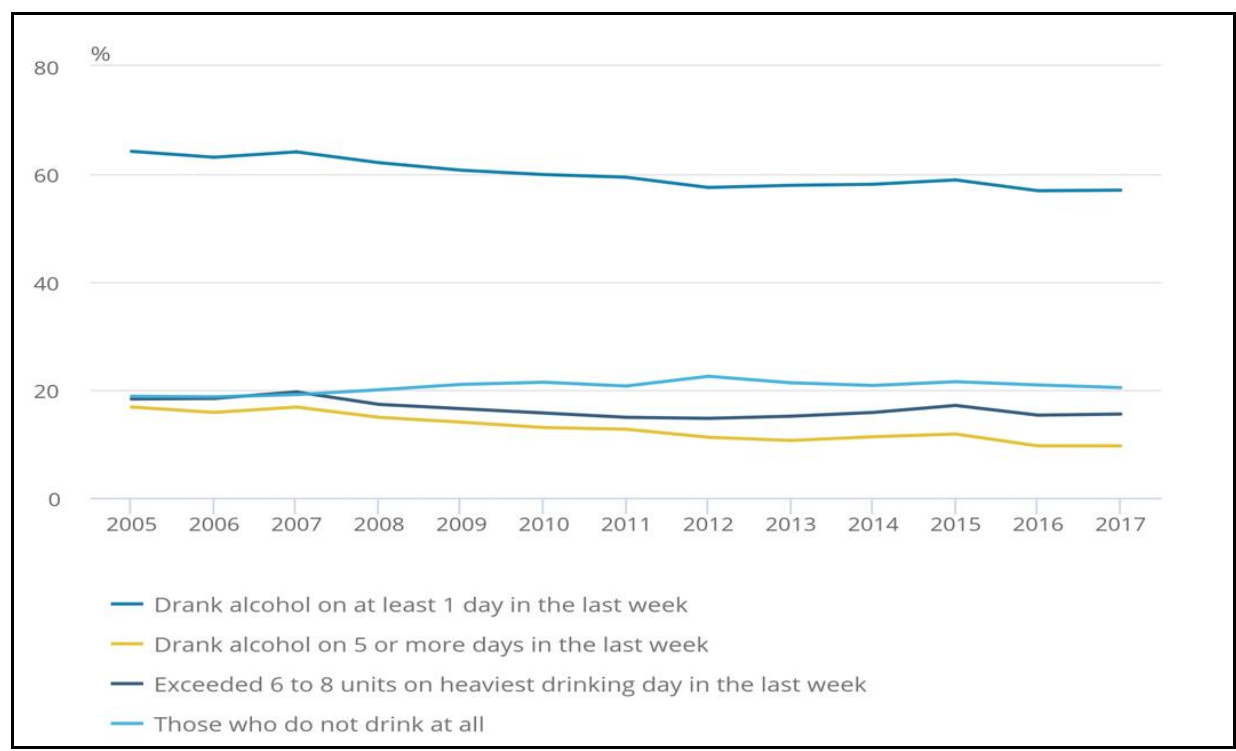

The study of Roberts et al across England and Wales from 2004 to 2012 (2) has reported mortality rates following acute admission of $23.4 \%$ for alcohol related liver disease and $35.4 \%$ for those with hepatic failure at 60 days after admission, seven times higher than following acute admissions with stroke and eight times higher than for acute myocardial infarction (MI). The early deaths were directly related to complications of liver disease. Mortality was significantly lower for patients seen by consultant hepatologists and gastroenterologists and for patients admitted to transplant centres or larger hospitals. At five years following admission, mortality was $61.8 \%$ with alcohol related liver disease and $57 \cdot 1 \%$ for hepatic failure. Using the same methodology to extend the analysis from 2004 to 2017, Public Health England have shown that for England the very high 60 day mortality remains unchanged (Figure 3)

Figure 3: Mortality rates following admission with alcohol related liver disease and hepatic failure 20042017

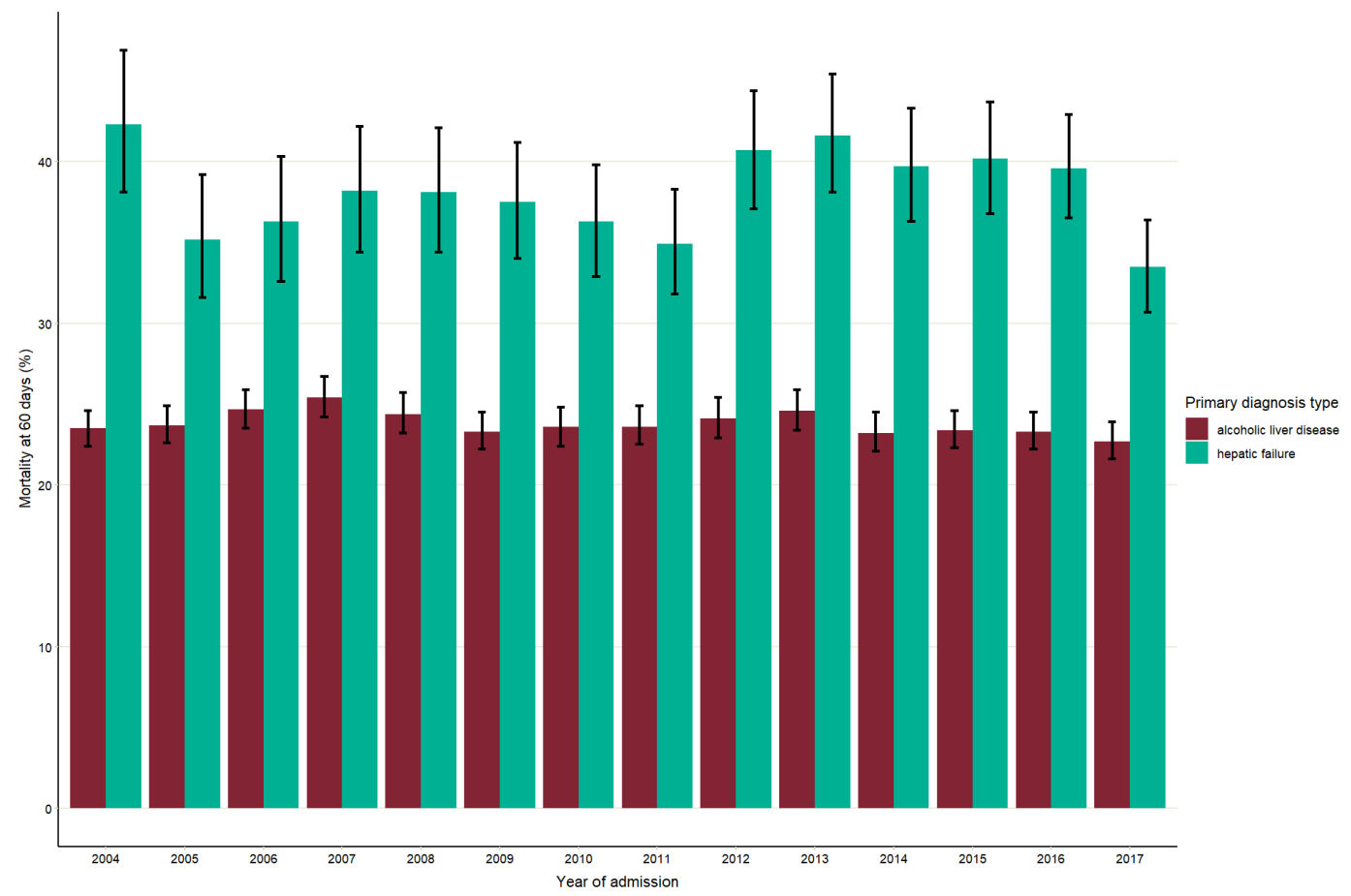

A recent meta-analysis(8) suggests that the true prevalence of alcohol-related conditions in NHS hospitals is approximately 20-30 times higher than the official government statistics (ie 24-36million per annum), most likely 
due to an lack of training of staff in the NHS to identify, diagnose, treat and record the number of people with alcohol related conditions(8).

Analysis of data from a large teaching hospital in the South of England showed no evidence of improvement in survival of cirrhosis admissions over the last 15 years (Figure 4), echoing the results of an older study which showed no improvement between 1959 and 1976 (9). In previous reports, we presented analysis of Dr Foster data showing that in-hospital mortality for liver disease is consistently falling year on year. But the fact that improvements in hospital care have not translated into improvements in long-term survival of cirrhosis patients is a sad reflection of overall current UK practice. The majority of patients with cirrhosis are not picked up in primary care but remain undiagnosed until the first admission to hospital with complications of cirrhosis. Around one third die within months of first presentation. The legacy system of arranging cirrhosis follow-up in secondary care is also not fit for purpose. The audit carried out in Southampton of follow-up in the cirrhosis cohort (Figure 4) where the hospital policy was to review every cirrhosis patient at six monthly intervals in order to arrange endoscopy and ultrasound surveillance, in compliance with NICE guidelines(10). found that of 3010 cirrhosis patients, $13 \%$ only had been seen in clinic within the last six months and $73 \%$ had not been seen for three years; $47 \%$ had never been seen at all. Only $37 \%$ had a record of liver ultrasound within the last year and $37 \%$ had not had an endoscopy within the last three years. Overall, $63 \%$ of patients diagnosed with cirrhosis were missing out, essentially identical findings to a similar audit performed 5 years earlier.

Using research funding from British Liver Trust LOCATE project, a virtual liver clinic has been piloted over the last year and preliminary indications are that by using data-based recall, sharing care with GPs and establishing virtual clinics, care can be dramatically improved(11). Liver centres need to must urgently put into place a regular audit of the efficiency of their follow up procedures and make the appropriate changes to ensure equality of access. This is particularly important for patients with alcohol related liver disease and are still drinking who will DNA appointments if they have been dealt with insensitively by medical staff previously. A situation that can potentially be avoided when combined liver/alcohol follow up is arranged through an alcohol care team. Over the last year in a pilot project as part of the LOCATE study, hepatoma and varices screening for a subset of patients were arranged using a data system developed by Alan Hales via a virtual clinic(11). Preliminary indications are that this system is successful and extremely cost effective.

Fig 4: Survival of patients following first admission with a diagnosis of cirrhosis categorised into three year cohorts

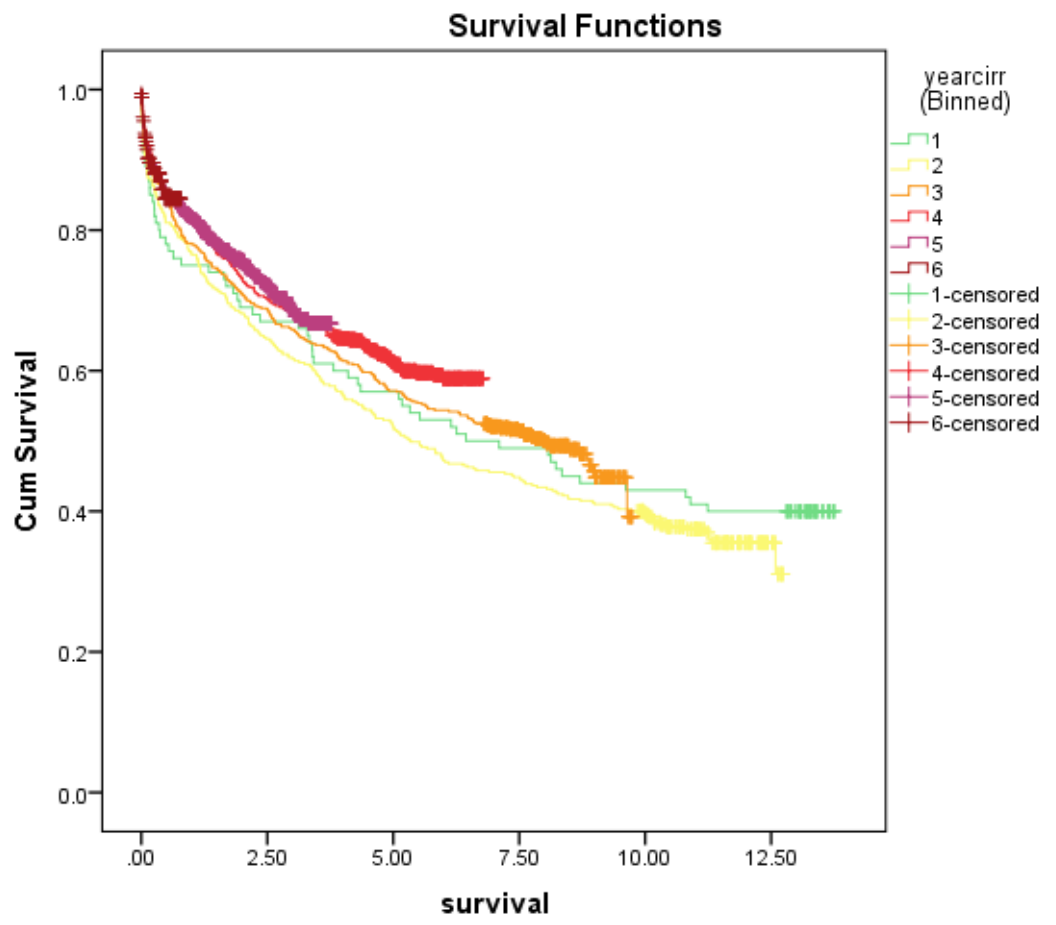

Data was extracted from the Patient Administration System (PAS) at University Hospitals Southampton for consecutive admissions with a primary or secondary diagnosis of cirrhosis according to ICD 109 coding. Date of death is regularly updated to the PAS system from the national Mortality Tracing Service and enabled survivals to be calculated and a Kaplan Meier survival analysis to be performed. Data obtained from several other large UK liver centres previously is not presented but showed a similar picture.

Community Alcohol Services

Alcohol Care Teams and 
The NHS long-term plan, published in January 2019(5), includes a commitment to establish and optimise alcohol care teams (ACTs) in district general hospitals over the next five years. NHSE and NHS Improvement (NHSE\&I) will be targeting the worst affected hospitals with additional monies(5). Funding is to come from the clinical commissioning groups' health inequalities funding supplement, working in partnership with local authority commissioners of drug and alcohol services from 2020/21.In addition, a $£ 4.5$ million innovation fund was launched in 2018 by the Department of Health and Social Care for local projects working with children and families affected by alcohol(12). NHSE will apparently be providing guidance on implementation which is going to take, in the Commission's view, considerable and detailed effort. Moriarty identifies eleven components as essential in ACTs (see Box 1)(13) and in a 2009 survey of ACTs in London hospitals, only $42 \%$ had an alcohol support nurse (ASN) and 10\% a lead clinician(14); in 2016, 83\% of UK hospitals had ASNs(15), and in 2019, around $60 \%$ have a clinician lead although many hospitals are still not staffed to provide a 7-day ASN service.

\section{Box 1: Key components of Alcohol Care Teams(13)}

1. A clinician-led, multidisciplinary alcohol care team, with integrated alcohol treatment pathways across primary, secondary and community care;

2. Coordinated alcohol policies for emergency departments and acute medical units;

3. A 7-day alcohol specialist nurse service;

4. Addiction and liaison psychiatry services;

5. An alcohol assertive outreach team for frequent hospital attenders;

6. Specialist consultant hepatologists and gastroenterologists with expertise in liver disease;

7. Collaborative, multidisciplinary, person-centred care;

8. Quality metrics, national indicators and audit;

9. Workforce planning, training and accreditation;

10. Research, education and health promotion for the public and healthcare professionals;

11. Formal links with local authority, public health, clinical commissioning groups, patient groups, and other key stakeholders.

The $9 \%$ of people in England with alcohol dependence account for 59\% of all alcohol-attributable hospital admissions (16). Alcohol assertive outreach treatment (AAOT) for the estimated 54,369 patients in England with alcohol-attributable hospital admissions has an implementation cost of $£ 161$ million, with cost savings of around $£ 575$ million, the return on investment (ROI) being $£ 3.42$ for every $£ 1$ spent(17) and also strongly correlates with the index of multiple deprivation $(\mathrm{r}=0 \cdot 74)(17)$. With the emphasis of the prevention Green Paper on reducing health inequalities, the Commission's view is that ACTs and AAOT should be rolled out to all DGHs with a demonstrated patient burden of alcohol-related illness. This would facilitate achievement of the United Nations General Assembly Sustainable Development Goals (SDGs), especially SDG 10, which aim to reduce global health inequalities and provide a more equitable and sustainable future for all people by 2030 .

The alcohol and tobacco CQUIN (Commissioning for Quality and Innovation) was introduced in 2017 and is being implemented across all inpatients in mental health, community and secondary care NHS trusts(18). Latest data shows that overall, $25.2 \%$ of screened inpatients are drinking at increasing/higher risk/possible dependent levels in mental health trusts, $14.2 \%$ in acute trusts, and $6.4 \%$ in community trusts (personal communication). These figures are to be compared to $25 \%$ of the general population who are drinking at increasing and higher risk levels and dependence.

\section{Reduction in community treatment and addiction services}

Since the introduction of the Health and Social Care Act, combined with cuts to the government's Public Health Grant to local authorities, there has been an $18 \%$ ( $£ 162$ million) reduction in funding to community addiction treatment services in England, with ten local authorities reducing by at least $40 \%$ (19) resulting in a $22 \%$ reduction in the number entering specialist alcohol treatment, and a 52\% reduction in access to specialist inpatient alcohol detoxification(19). England now has less than half the level of access to specialist alcohol treatment compared to Scotland and Wales (Table 1). $82 \%$ of people with alcohol dependence do not currently access specialist treatment(19).

Table 1: Alcohol treatment access ratios across the United Kingdom 2017/18 compared to 2016/17 


\begin{tabular}{|l|l|l|l|l|l|}
\hline Country & $\begin{array}{l}\text { Number } \\
\text { accessing } \\
\text { treatment for } \\
\text { alcohol only }\end{array}$ & $\begin{array}{l}\text { Number of F10 } \\
\text { alcohol hospital } \\
\text { admissions }^{2}\end{array}$ & $\begin{array}{l}\text { Rate of F10 } \\
\text { admissions } \\
\text { 100,000 } \\
\text { population >18 } \\
\text { years }\end{array}$ & $\begin{array}{l}\text { Treatment access } \\
\text { ratio } \\
\text { admissions/ F10 } \\
\text { treatment access) }\end{array}$ & $\begin{array}{l}\text { Treatment } \\
\text { access ratio } \\
(\mathbf{2 0})\end{array}$ \\
\hline Scotland & 26,107 & 27,025 & $614 \cdot 9$ & $1 \cdot 0$ & $1 \cdot 1$ \\
\hline Wales & 7,678 & 8,804 & $307 \cdot 5$ & $1 \cdot 1$ & $1 \cdot 2$ \\
\hline England & 75,787 & 197,460 & $451 \cdot 3$ & $2 \cdot 6$ & $2 \cdot 4$ \\
\hline Northern Ireland & 2,577 & 9,963 & $694 \cdot 6$ & $3 \cdot 9$ & $3 \cdot 9$ \\
\hline United Kingdom & $\mathbf{1 1 2 , 1 4 9}$ & $\mathbf{2 4 3 , 2 5 2}$ & $\mathbf{4 6 7 \cdot 0}$ & $\mathbf{2 \cdot 2}$ & $\mathbf{2 \cdot 1}$ \\
\hline
\end{tabular}

${ }^{1}$ Excludes concurrent drug misuse as a reason for treatment.

2Primary or secondary diagnosis of ICD10 F10 'Mental and Behavioural Disorders due to Use of Alcohol'. This is a proxy measure of the prevalence of alcohol dependence in the general population.

${ }^{3}$ Note the treatment access ratio - the number of F10 admissions to NHS hospitals divided by the number of people accessing specialist alcohol treatment -worsened in England and the UK as a whole.

Another consequence of the cuts has been a $48 \%$ reduction in the number of NHS specialist addiction consultants in England, and a 60\% reduction in the number of specialist addiction trainees(21).

Public Health England (PHE) announced in March 2019 a $£ 6$ million capital fund to enable local authorities to invest in improving access to alcohol treatment services and of the 23 projects commissioned, seven comprised purchase of elastography machines to enable rapid identification of liver disease(22).

\section{Need for a Comprehensive Strategy to Reduce Alcohol Consumption}

Not only are alcohol related deaths rising(23) but the number of people harmed by someone else's drinking is estimated at one-in-five according to a recent Public Health England (PHE) report(24). Much evidence is available of effective solutions that could be adopted, with action on price, availability and marketing at the top of the list of interventions (25). The 50pence minimum unit price (MUP) of alcohol it is estimated would reduce alcohol attributable deaths in England by $4.3 \%$ and associated healthcare costs by $2.3 \%(26)$. Strong consensus exists amongst health, social care, justice and civil society groups that such measures are urgently needed to tackle alcohol harm(27). A comprehensive alcohol strategy by Government should follow the recommendations of WHO and tackle the affordability, availability and promotion of alcohol, aiming for a 10\% reduction in harmful use of alcohol by 2020(28).

The UK Government has repeatedly failed to grasp many opportunities to take meaningful action to prevent alcohol harm. Plans for a UK alcohol strategy announced in May 2018(29) have been put on hold whilst the Chancellor of the Exchequer has made alcohol more affordable by cutting duty in the October Budget 2018(30) (a decision that resulted in a loss of £1billion to HM Treasury, equivalent to the annual salaries of 40,000 nurses(31). A 2\% above inflation increase in alcohol duty would result in 4,710 fewer alcohol related deaths and 160,760 fewer hospital admissions between 2020-2035, according to the latest modelling report(32), as well as raising substantial funds to support over-stretched local public health budgets.

The Government's Prevention Green Paper(3), whilst acknowledging that alcohol harm is rising, made no commitment to address the major drivers of ill-health and inequality linked to alcohol(3), devoting only one and a half pages of the 78 page document to alcohol consumption. No actions were proposed to target the $4 \%$ of the adult population who are the heaviest drinkers that account for 30\% of all alcohol consumed. The Department of Health and Social Care (DHSC) are to review the evidence for increasing the alcohol-free descriptor threshold from $0.05 \% \mathrm{ABV}$ to $0.5 \% \mathrm{ABV}(3)$. Such a move, however, will have no impact on the high-risk drinkers who are most in need of specialist treatment and support services.

Another missed opportunity for Government to act in the interests of public health was the $1^{\text {st }}$ September 2019 deadline given to alcohol companies to display up to date and accurate information on product labels about the 
health risks associated with alcohol(33). The majority of drinks sold do not carry the latest Chief Medical Officer's low risk drinking guidelines, leaving consumers in the dark about the latest health advice(34). In August 2019, a month before the Government's deadline to display the guidelines on labels, the alcohol industry's Portman Group announced it was 'encouraging' its members to display the CMO advice on product labels(35) but no timelines were offered for implementation..

\section{Disease Consequences of High Obesity Prevalence}

In 2017, the prevalence of obesity in adults was $29 \%$, representing a $3 \%$ annual increase, whilst for children in Year 6 and Reception the figures were $20.1 \%$ and $9.5 \%$ respectively. Of particular concern is the increasing gap in obesity prevalence between the least and most deprived deciles, with a five percentage point increase for Year 6 children between 2006/07 and 2017/18(36). Obesity related disorders remain a major contributor to hospital workload, with 10,660 admissions directly attributable to obesity and over 700,000 admissions where it is a primary or secondary diagnosis (a 15\% annual increase). The 6,627 admissions for bariatric surgery in 2017/18 are an increase of $2 \%$ over the previous year(36) but represent treatment of less than $2 \%$ of eligible individuals.

The National Cardiovascular Intelligence Network (NCVIN) estimates that there are 4 million people with Type 2 diabetes in England, of whom 2.9 million have been diagnosed with the condition(37). Obesity is estimated to be responsible for 80 to $85 \%$ of someone's risk of developing Type 2 diabetes and the condition is responsible for more than 3000 amputations, over 19,000 strokes and almost 15,000 myocardial infarctions every year(38). At least 10,000 people in the UK have end stage renal failure as a consequence of their diabetes and more than 1,700 have their sight seriously affected by their diabetes each year. Type 2 diabetes incurs almost $£ 9$ billion of costs to the NHS annually, around $9 \%$ of the total NHS budget (39). Of particular concern is the marked increased in prevalence in children and young adults, with 745 people under the age of $25 y$ rs reported as having Type 2 diabetes in England and Wales in 2017/18(40). End-stage non-alcoholic fatty liver disease (NAFLD) is a growing clinical problem in the UK, placing major challenges on the NHS. In particular cases of NAFLD with decompensated cirrhosis are rising such that they are now also posing an increasing burden on transplant services(41).

The Chief Medical Officer published a report in October that made clear the magnitude of the challenge of achieving the Government's ambition to halve child obesity by 2030 and provided 49 wide-ranging recommendations designed to drive fundamental changes in the environments that shape our dietary and physical activity behaviours. This will involve much greater regulation of the food industry, major restrictions on advertising and marketing of unhealthy products and transformation of our towns and cities to create safe, appealing environments in which children can walk, cycle and play(42). The Department of Health and Social Care has proposed a number of actions $(43,44)$ in Chapter 2 of the Child Obesity Plan in 2018(45) including policies to reduce both total calorie consumption and sugar intake and to restrict advertising and marketing of unhealthy food to children. However, at the time of publication these were still under consultation and had not yet been implemented. The recently published Green Paper on Prevention(3) contains a range of proposals including labelling, food reformulation, weight management services and physical activity promotion but gives little guidance on how these will be translated into effective policies which will require much more intensive policy action than has been seen to date (46). The only new regulatory commitment was to consult on ending the sale of energy drinks to the under $16 y$ rs age group.

The persistent framing of obesity as merely the result of individual choice needs to be challenged. While decisions about both diet and physical activity are ultimately made by individuals, the 'choices' available to people depend on a wide variety of factors. Those behavioural decisions are primarily driven by environments that promote overconsumption of food and under-expenditure of energy. It is only by tackling these obesogenic environments that equitable reductions in prevalence and consequent health benefits will be achieved and sustained.

\section{Marketing of Unhealthy Food and Alcohol}

There is unequivocal evidence that the marketing of unhealthy food to children leads to childhood obesity (47) and that marketing of alcohol leads to an uptake of drinking and increased consumption in young people (48). Similar evidence for the marketing of cigarettes and smoking in young people led to comprehensive and effective global bans on tobacco as part of the International Framework Convention on Tobacco Control (49). In contrast, the food and alcohol industries have been allowed to 'self-regulate' despite evidence that this does not effectively reduce childhood exposure to adverts (50). In an increasingly digital age - children aged 12-15yrs are online for an average of 21 hours each week in the UK (51) - teenagers are exposed to promotional activities which include paid-for advertisements, product placement, content sharing by peers or the activities of social media influencers. 
These targeted messages are then narrowcast to mobile devices without parental control or oversight. Young people cannot always recognise these marketing tactics as having a commercial goal or distinguish them from organic(52). The spend on digital marketing has increased year on year, in 2016 receiving the largest share of advertising spending in the UK(53).

Social media and other operators have created sophisticated datasets to target consumers but between the commercial operators with products to sell and their young target audience, marketing messages disappear into a black box marketplace where individual messages are sold on by a myriad of intermediate agencies - supply-side platforms, data exchanges and demand-side platforms - which bid for advert impressions (54). Though advertising messages could be tagged and traced, there is no facility to do this within the current marketplace. Effective forms of age verification do exist but these are not currently used to filter marketing traffic with the result that no one knows if a marketing message is seen by a child or an adult.

Earlier this year the World Health Organisation published an outstanding report including pragmatic solutions (54), the CLICK tool providing the conceptual framework needed to understand and monitor exposure of children to digital messages(47). Along with estimating exposure, WHO suggest there should be effective age verification and message tagging, coupled to achieve effective regulatory regimes. Policy makers need to be made aware that the digital marketplace in the UK is almost entirely un-regulated and mandatory Government measures to reflect this unique environment are urgently needed.

\section{Obesity as Cause of Common Cancers}

Most cancer types have multiple risk factors but $38 \%$ of the 22,800 cancer cases annually in the UK are preventable(55) including 49\% of liver cancer (around 2,800 cases). Overweight and obesity (body mass index [BMI] 25+) contribute the highest proportion of liver cancers (around 1,300 cases annually) and is second only to smoking as the leading preventable cause of cancer in the UK, with alcohol consumption ranking sixth(55). Overweight and obesity have a definite causal link with 13 cancer types, namely breast, bowel, oesophagus and kidney (high) liver, pancreas and uterus (moderate) and oral, ovary, myeloma and thyroid (low). Alcohol consumption is linked with seven cancer types $(56,57)$ with obesity having a synergistic effect and adding to the risk of breast, bowel, liver and oesophagus $(58,59)$. The other three - mouth, upper throat and larynx - having a specific and distinct association with excess drinking.

\section{View of Commission Members on the Government's Prevention Green Paper (3)}

The comments of two members of the Commission are quoted in full as a reflection of the view of the Commission as a whole and of many comments by professional bodies and agencies beyond the scope of this report. The first is by Professor Martin McKee: "In July 2019 the Department of Health and Social Care finally, and very reluctantly, published its Green Paper on prevention Accounts from Whitehall insiders report how the Health Secretary sought to withhold it and then when Theresa May, Prime Minister at the time, decided it should be published, sought to have the Department's name removed. Unusually, when it did appear, it was not accompanied by a press release. The widespread scepticism with which it was greeted(60) has been encouraged by news that the new Prime Minister has appointed advisers linked to lobby groups funded by manufacturers of harmful products(61).

The section on alcohol begins by saying that "Most people who drink, do so responsibly". A recent study examined how the concept of responsible drinking is almost exclusively used by the alcohol industry and groups it funds(62). Until now, this term very rarely appeared in government documents. That study also found that it was often used in a context where government guidelines were being undermined and where the alcohol industry was portrayed as pursuing corporate social responsibility.

The government's proposals are extremely weak and ignore the evidence favouring population-based measures, such as taxation, reductions in availability, and restrictions on marketing which, as shown in the previous Lancet Commission on Liver Disease, are all strongly opposed by the alcohol industry.(20) There are three main proposals. The first is to make people more aware of alcohol-induced harms through Public Health England's One You campaign(63). The second is to stress the value of an alcohol risk assessment in the NHS Health Check, another initiative criticised for lacking evidence of effectiveness(64). The third is the support children with alcohol dependent parents although, surprisingly for a consultation document, this has already been launched, in April 2018. A final section discusses collaboration with the alcohol industry to promote low alcohol products, without reference to the experience of the heavily criticised industry partnership in the Responsibility Deals, and in a major concession to the industry, promises to review the potential to redefine "alcohol free" to allow up to ten 
times the current level of alcohol. In summary, this is a document that could easily have been written by the alcohol industry and is almost wholly devoid of a public health perspective."

The second comment is by Professor Harry Rutter: "The Government's recent Prevention Green Paper is framed in terms of individual responsibility and personalised approaches, diverting focus away from the commercial and structural drivers of ill health in the population that so urgently need to be tackled. However, there are some positives including proposed actions on obesity which represent solid work by the DHSC and PHE obesity teams but it goes nowhere near far enough."

\section{Planned Proposals to Improve Hospital Based Care}

The Hepatobiliary Clinical Reference Group (HPB CRG) which advises NHSE on the management of patients with advanced liver disease has made a number of recommendations for major changes in response to the increasing volume of patients with cirrhosis and variation in outcomes between providers. The complexity of managing patients with acute on chronic liver failure and decompensated cirrhosis requires an experienced, diverse clinical team with 24-hour care provided by specialist hepatologists supported by appropriately trained intensivists, radiologists, dieticians, nurses and pharmacists as well as ready access to liver transplantation services. Such services cannot be provided in every hospital which admits patients with cirrhosis and to ensure that all patients have equal access to high quality care, the CRG has recommended that regional networks are established with each hospital linked to a centrally supported specialist centre. The establishment of a comprehensive series of networks with appropriate funding and support and is strongly recommended by the Commission but as referred to earlier, the proposals continue to await endorsement by NHSE, with no date for implementation.

To facilitate the development of the networks, the HPB CRG have recommended a new service specification for specialist providers of liver services which should lead to the development of a more targeted referral pathways. Patients with advanced liver disease admitted to any hospital in the country would receive early, algorithm based, review (including use of the well-established 'cirrhosis care bundle') followed by discussion with the local liver lead and, if appropriate, with the regional liver centre. An example of this working is in East London where a Barts Health NHS Trust hepatology consultant is based at Queens Hospital in Romford and provides out-patient and in-patient advice on specialist liver care for the region.

To improve current provision of care for patients with decompensated cirrhosis, NHSE has offered a new incentive scheme (CQUIN) which rewards trusts who introduce network based approaches to the management of patients with cirrhosis (65). Monitoring and evaluation of the changes will be through a new 'Cirrhosis Dashboard'(66) which provides information on a range of metrics relating to the quality of care for patients with liver disease and will be sent to trust chief executives every quarter. An analysis of data from the NHSE cirrhosis dashboard from June 2018 to April 2019 of the 40 trusts currently commissioned to provide specialist liver services, showed that a large number (over 120) are continuing to manage patients with cirrhosis although many report relatively small numbers of patients - 20 trusts admitted fewer than ten patients a quarter to HDU/ITU and 76 trusts admitted fewer than 20 such patients. $7.5 \%$ of the patients with decompensated liver disease admitted as an emergency died in hospital with a mortality of $8 \%$ in non-specialist trusts compared to $6.6 \%$ in commissioned, specialist centres.

Emerging therapeutics (such as next generation anti-inflammatories for alcoholic hepatitis) and technologies (including the long-awaited development of 'liver assist' devices that deliver meaningful benefits) are likely to further enhance the differences in outcomes between the high and low volume centres.

\section{Opportunities to Improve Post-hospital Discharge Care}

Cirrhotic patients who survive an emergency admission to hospital with ascites are frequently readmitted within a month of discharge and while some readmissions are inevitable due to continued disease progression, many are potentially avoidable. An analysis of 120,000 cirrhosis admissions revealed ascites or hepatic encephalopathy (HE) to be the major predictors of unplanned readmission at 30 or 90 days(67). Readmissions are often attributable to patients' insufficient understanding of their medications or early recognition of symptoms and both the American Association for Study of Liver Diseases (AASLD) and European Association for Study of the Liver (EASL) guidelines emphasise the importance of education (68). In one study, only $6 \%$ of HE patients and their carers understood the purpose of drug therapy or its side effects(69) and a survey of 150 cirrhosis patients found awareness of $\mathrm{HE}$ and its treatment was lower than for any other complication(70). The relatively simple intervention of providing educational booklets and structured post-discharge care needs to be more widely promoted by NHSE and adopted by hospital trusts. 
Excellent results can be obtained by trained Nurse Specialists for large volume paracentesis (LVP) performed for diuretic refractory ascites as elective day-case procedures. In Cambridge, this has saved over 500 bed-days per year, at greater convenience for the patients. Nurse-led paracentesis is also offered in other locations, including Brighton, Bristol, Cardiff, Gloucester, London, Newcastle, Plymouth, Portsmouth, Southampton and Truro and should be included in planned care strategies for all hospitals treating liver patients. The value of this is further shown by a recent analysis of over 13,000 people with cirrhosis in their last year of life, with day-case services giving lower costs and a lower probability of patients dying in hospital (71). The use of paper-based or electronic decision support tools, prompting hospital staff to follow guidelines, has the potential to increase the proportion of patients discharged on appropriate medications, leading to fewer readmissions (67) and the comprehensive cirrhosis "discharge care bundle" now being piloted are other approaches meriting wider scale implementation.

\section{Failure to Increase Number of Liver Transplants}

The 1003 liver transplants in 2018-2019 (72) represent a reduction in activity compared with the 2017-18 total of 1043. Disappointing also, with the potential for machine perfusion to increase the number of utilised organs, only $8 \%$ (63) of adult deceased donor first liver transplants were reported to have involved normothermic or hypothermic machine perfusion, with no use of it in two of the centres. At the end of 2018-19 the waiting list had risen by $20 \%$ (432 from 359) and during 2016-17, $10 \%$ of new elective patients listed for liver transplantation, died or had to be removed from the list.

The three monthly reviews of the National Liver Offering Scheme (NLOS) introduced in March 2018 for brain death donor (DBD) organs based on a possible transplant benefit score at five years, showed a fall in the median waiting time for transplantation to 39 from 72 days but the acceptance rate of offers made through the scheme to specific matched recipients was lower than predicted at $30 \%$. This has been accompanied by an increase ( $8 \%$ to $28 \%$ ) of DBD livers not accepted for named recipients. New patients added to the waiting list since the inception of the scheme are more likely to be transplanted and as predicted by the modelling exercise, there is an undesirable trend towards older patients being transplanted and a reduction in those with HCC.

Results of the soft version, opt-out legislation introduced in Wales in 2018 are also disappointing with no increase in number of donor organs, though there has been an increase in donor consent rates by families which are now exceed those in England. With the implementation shortly of opt-out in England in spring 2020 and a wider uptake of organ perfusion strategies in increasing organ utilisation, the opportunity would be taken to tackle unmet needs for liver transplantation such as service evaluations on chronic liver failure, hilar cholangiocarcinoma and neuroendocrine tumours, but as yet no definite proposals have been agreed.

Currently there is no approval for additional liver transplant centres to increase transplant capacity. NHSE are allowing consideration of aspirant market entrants to replace or add to the existing providers. A number of aspirant centres including Plymouth, Oxford and Liverpool are working towards this but none are as yet in place and although it is difficult to us the term failure when overall results of transplant procedures are so good (96-97\% one year survival) nevertheless the demand is not being met as it could be.

\footnotetext{
Major Vacancies in Workforce of Consultant Hepatologists and Specialist Nurses

The goal for an effective specialist hepatobiliary service is to have two hepatologists serving 250,000 people or $0 \cdot 8$ whole time equivalent (WTE) per 100,000 population. Based on recent (2017) estimates, 221 hepatologists or 306 gastroenterologists with an interest in Hepatology are leading these services although the number is variable across the UK, with Scotland, England, Northern Ireland and Wales having 0.39, 0.35, 0.22 and 0.08 hepatologists respectively per 100,000 population. Optimising levels of consultant Hepatologists requires an increase to $528 \mathrm{WTE}$, equivalent to 222 more posts. For this, liver appointments (and funding) will need to be prioritised and the rate of consultant expansion improved beyond the $1.6 \%-4.9 \%$ annually for gastroenterology in the past decade. There are also concerns about the number of transplant surgeons that will be needed to expand capacity of existing and new programmes, with availability of a greater number of donor organs.
}

For more than a decade speciality training and accreditation in hepatology has lagged behind that for Gastroenterology. The ratio of specialist trainees in Hepatology to luminal gastroenterology trainees should, it is recommended, be increased from the current 1 in 3 ratio, thereby enabling NHS Trusts to prioritise the filling of vacant posts. Even wider variation exists across UK in the number of liver nurse specialists whose remit needs to be expanded to include day-case paracentesis and transient elastography (TE) services at the interface of primary and secondary care.

Detection of Early Disease by Screening in Primary and Community Care 
The online toolkit for GPs (73), co-ordinated by the Royal College of General Practitioners (RCGP) and funded by the British Liver Trust (BLT), continues to evolve with the recent addition of detailed GP commissioning recommendations for decision makers. It also includes, as highlighted in a national GP practice mailout, easily accessible information on latest national guidelines for interpretation of liver blood tests(74) and for use of transient elastography (Fibroscan) or Enhanced Liver Fibrosis (ELF) measurement of fibrosis based on AUDIT scores. The updated toolkit also includes 'quick link' buttons for easy access to guidelines/tools during GP consultations. Incentivising evidence-based care based on quality improvements, along with working with newly formed GP Primary Care Networks (PCNs) and their access to central funding for social and lifestyle prescribing represent further strong recommendations by the Commission.

Inclusion of the early detection programme in an updated NHS Health Check in line with NICE guideline NG50 Current Advice (10) will add significantly to the value of these checks. Exemplar proven models of care include the prizewinning Scarred Liver Project in Nottingham and the Southampton pilot pathway region-wide is leading to a reduction in hepatology referrals as well (http://www.stmaryssurgery.nhs.uk/info.aspx? $\mathrm{p}=10$ ). These need to be rolled out more widely in an effective context across the country as does the Tayside programme of Intelligent Liver Blood Tests (ILFTs) which, when increased serum transaminase or other abnormalities are found, also test for a raft of likely causes with the most likely diagnosis being fed back directly to the requesting GP (75).

\section{Box 2: The Scarred Liver Project, Nottingham}

The Nottingham pathway continues to attract significant numbers of referrals $(>3000$, since inception) with diagnosis of significant liver disease $(>20 \%$, TE $>8 \mathrm{kPa}, \sim 10 \%$ cirrhosis). The pathway has evolved to allow GPs and patients greater access to transient elastography based on risk factors alone. Any patient with type 2 diabetes, obesity, incidental fatty liver on ultrasound and a BARD score $>1$, or alcohol excess, can now go straight to transient elastography without the need for prior liver blood tests. Supported by the local Academic Health Sciences Network (AHSN), the pathway has been adapted for trials in other areas included within community drug and alcohol services in Chesterfield and within a regional primary care 'super-practice' (served population $200 \mathrm{k}$ ). The forward focus is on developing the brief lifestyle advice provided to all patients into a more supportive and sustainable behaviour change intervention. https://www.scarredliverproject.org.uk/ (76)

Each of the successful local schemes for earlier diagnosis have led to a reduction in unnecessary referrals to hospital-based consultant clinics with consequent cost savings. Demonstrating the effects on survival and state of health will require larger cohorts and longer periods of follow-up. 
Box 3: Hepatology vs community-based referrals in Southampton Primary Liver Care Pathway, 2015-

2019

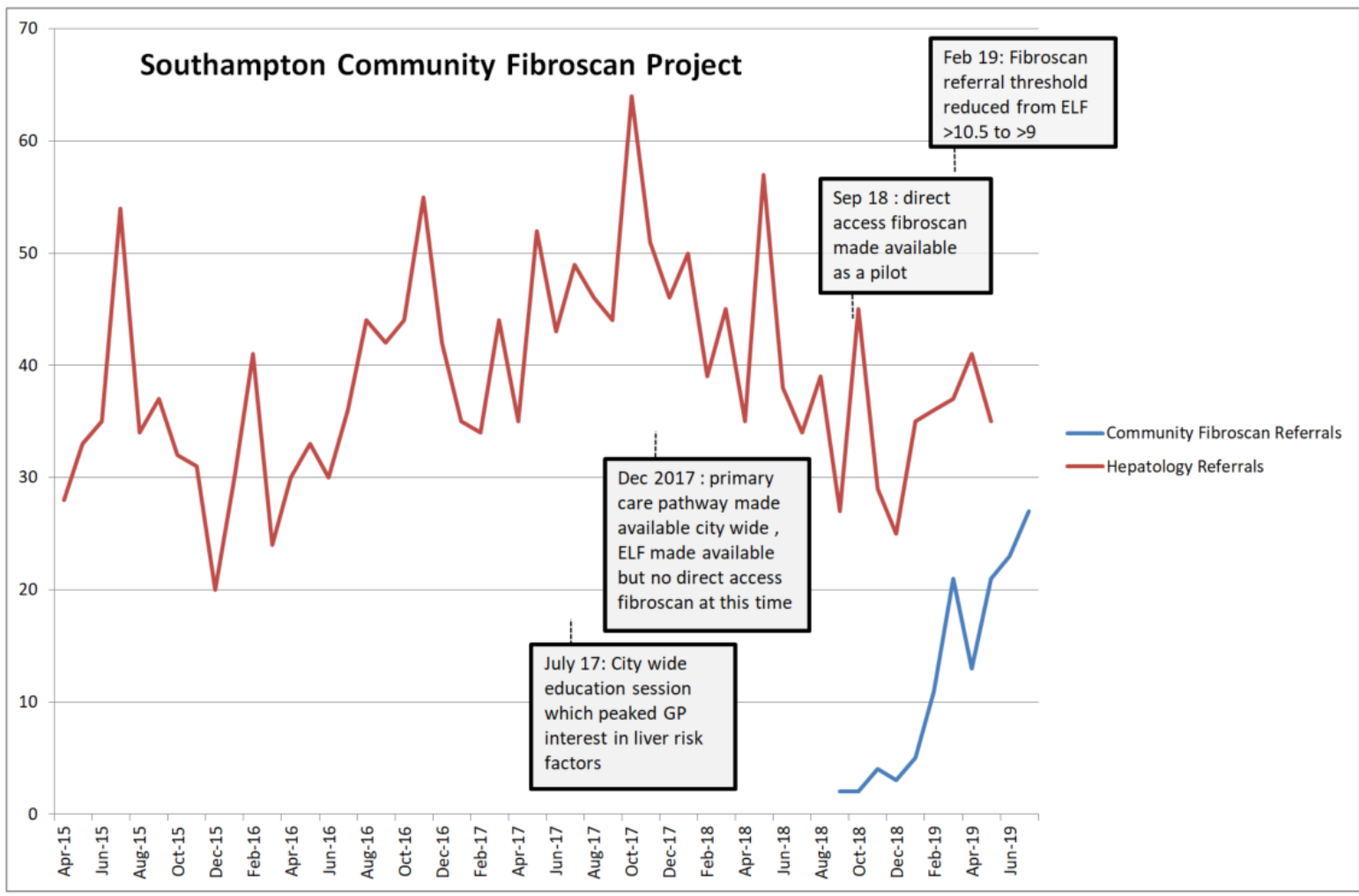

Combination of Potential Risk Factors for Liver Disease in a Primary Care Sample

With the proven evidence of a supra-additive, synergistic interaction between raised body mass index (BMI) and alcohol consumption in the development of liver disease(77), knowledge of the co-occurrence of both factors is of considerable relevance to health screening and public health policies. The Health Improvement Network (THIN), a large, representative database covering anonymised electronic medical records from over 700 general practices, was used to identify the occurrence of higher risk drinking, raised BMI, and both risks, in an adult sample attending a GP appointment in the financial year 2017/18 (personal communication, Clive Henn). Over 50,000 patients were identified who could benefit from a brief AUDIT and 1,500 patients were both obese and drinking at high risk levels. True levels were thought to be substantially higher. Such individuals, with their substantially increased risk of liver disease, should be prioritised for screening and management measures.

\section{Outcomes in Children with Liver Disease}

Death has become a rare outcome with mortality as low as $5 \%$ and is mainly in patients who were not candidates for liver transplantation or as a result of untreatable complications developing in later years after transplantation. An audit of all deaths occurring within the three UK paediatric liver centres (PLC) over the last five years (20142018) identified 137 deaths of whom 28 had undergone liver transplantation. Only four died of conditions unrelated to their liver disease. 76 of the 137 deaths were unexpected and such deaths remain a significant organizational issue, with $54 \%$ of deaths occurring outside the centres. It is recommended that all patients attending the three specialist centres should be reviewed for risk of death in childhood, allowing more focused treatment measures as well as palliative care to be planned.

\section{Poor Neurocognitive Ability}

Although patient and graft survival continue to be excellent, poorer cognitive ability, inferior educational achievement and employment outcome compared to peers has become a major, emerging concern. In a systematic review, $67 \%$ of children with liver disease and $82 \%$ of children following liver transplantation (LT) showed low average or abnormal scores on specific subscales of cognitive and behavioural measures (78). Whereas neurodevelopment is negatively affected by longer duration of the disease and waitlist time, it has been suggested that 
LT does not correct the impairment $(79,80)$. In addition, overall health related quality of life is inferior, and prevalence of mental health problems, in particular in adolescents and young adults is higher compared to the general population $(81,82)$. Lower educational attainment and special educational needs, present in $42 \%$ of paediatric LT survivors, are likely to impact on the development of self-management skills, including adherence to treatment, typically expected in an adult healthcare setting. Consequent on this employment, regarded as a health outcome, is inferior compared to the general population (Table 2). More attention, the Commission recommends, needs to be given to the concept of 'meaningful' survival - a state of complete physical, mental, and social well-being and not merely the absence of disease.

Table 2: Employment outcome in paediatric liver transplant recipients (data from Kings College Hospital, London only)

\begin{tabular}{|l|l|l|l|}
\hline & Employed & Unemployed & In education \\
\hline Paediatric liver transplant recipients $(\mathrm{n}=100)$ & $35 \%$ & $26 \%$ & $39 \%$ \\
\hline Paediatric liver transplant recipients $>21$ years $(\mathrm{n}=69)$ & $46 \%$ & $26 \%$ & $28 \%$ \\
\hline
\end{tabular}

\section{Latest Situation in the Four Nations}

Minimum Unit Price for alcohol at 50pence per UK unit $(10 \mathrm{mls} / 8 \mathrm{~g})$ was introduced in Scotland on $1^{\text {st }}$ May 2018 and NHS Health Scotland has published sales data for 2018, covering four months pre- and 8 months post MUP. Annual sales per adult at 9.9 litres pure alcohol(6) are now at the lowest level since the data series began in 1994. In 2016, per adult sales in Scotland were 17\% higher than in England and Wales whereas in 2018 this gap had narrowed to $9 \%$. A continuing issue is that sales data for Scotland, as with the rest of the UK, is not comprehensive with some retailers - including the discount supermarkets - not submitting data to market research firms. Scottish Health Action on Alcohol Problems (SHAAP) has called for a system where there is a legal requirement for sales data to be provided. Published annual mortality data for 2018 (83) showed a 1\% increase in all alcohol specific deaths with the $3 \%$ reduction in alcohol sales. The 2019 mortality data which will become available in mid-2020, would be expected to have fallen. Zhao and colleagues working with Canadian data estimated that the full effect of price increases on mortality are seen after 3 years $(84)$.

With the early identification of liver fibrosis fundamental to reducing progression of cirrhosis, the Scottish Government has adopted the Tayside piloted "intelligent LFT system" (iLFT) referred to earlier which is now being rolled out across Scotland.

In Wales, implementation of legislation for Minimum Unit Price has been delayed due to an objection made to the European Commission by Portugal and the plan is to introduce it in early 2020. The Irish Republic has passed a comprehensive alcohol Bill (85) including marketing restrictions and MUP but no implementation date has been set and new legislation in Northern Ireland is not expected until devolved Government is re-established.

\section{Conclusions}

The underlying aim of the present report is to emphasise yet again the important areas that need to be tackled with the continuing rise in health burden from liver disease consequent on lifestyle issues of excess alcohol consumption and obesity, The report again stresses the present need for fiscal regulatory measures by Government if excessive consumption of alcohol and food is to be reduced and lives saved. The first results of introduction of MUP in Scotland confirm how specifically targeted the MUP is on heavy drinkers, with a dramatic decrease in sales of high strength low cost alcohol products and the value of the alcohol duty escalator was shown previously over a 5 year period. The latest report of Russia's alcohol policy, with improvements in survival expectations, is evidence of the effectiveness fiscal measures targeting price, availability and marketing, in reducing consumption in a country(86). The finding that the levy on the sugar content of drinks is giving less than half the anticipated revenue to the Exchequer because of reformulation of products by the industry, shows also what is achievable by fiscal initiatives. 
In the Commission's view, without these measures the chances of achieving 5 extra years of healthy living, as targeted by the Secretary of State for Health and Social Care, is very unlikely. Furthermore, with the extraordinary lack of awareness of liver disease by the public shown in the new ComRes survey, putting the entire responsibility on the individual to control lifestyle excesses, as recommended in the Government's recently published Prevention Green paper, is unlikely to be successful in comparison with the population directed regulatory initiatives described.

The latest unacceptably high e mortality figures given in the report for severely ill liver patients admitted to DGHs is an urgent reminder of the need for NHSE to implement the masterplan for hospital services based on regional specialist centres, each linked to networks of DGHs through operational delivery networks (ODNs). Along with this is the wider use of discharge care bundles for guiding further treatment on an outpatient basis and reducing the high hospital readmission rates. The effectiveness of a number of locally driven schemes based on availability of elastography also shows a way forward for the earlier detection of liver disease in general practice. Introduction of appropriate financial incentives for its inclusion as part of the Health Check would ensure wider uptake and is strongly endorsed by the Commission.

Finally, the financial appraisals by the Commission show how costly the health burden is to the country and the savings to the Revenue that would be obtained from the fiscal measures suggested, should be a powerful influence too in getting recommendations accepted by the higher echelons of Government.

\section{Box 4: The Commission's Key Messages and Priorities for 2019-20}

\section{Key Messages:-}

- There is a further increase in the disease burden from excess alcohol consumption and overweight/obesity

- The mortality for acutely sick liver patients admitted to District General Hospitals is unacceptably high

- An early detection programme in general practice based on elastography is a feasible and logical proposition

- The public awareness of liver health hazards is extraordinarily poor as shown in the new ComRes poll Key Priorities:-

- Convincing upper echelons of Government of the need for fiscal regulatory measures including MUP, tax duty escalator and levy on food content

- Implementation by NHS of Masterplan for hospitals and day-care treatments based on specific guideline bundles

- Further investigation into causes of cognitive impairment and consideration of meaningful survival in paediatric liver disease

- Widening the impact of expert opinion on the present burden of liver disease through greater coordination with the Academy of Medical Sciences, the Royal Colleges and Royal Society of London

References:

1. O'Donnell A, Anderson P, Jane-Llopis E, Manthey J, Kaner E, Rehm J. Immediate impact of minimum unit pricing on alcohol purchases in Scotland: controlled interrupted time series analysis for 2015-18. BMJ. 2019;366:15274.

2. Roberts SE, John A, Brown J, Napier DJ, Lyons RA, Williams JG. Early and late mortality following unscheduled admissions for severe liver disease across England and Wales. Aliment Pharmacol Ther. 2019;49(10):1334-45.

3. Department of Health Government, HM. Advancing our Health: Prevention in the 2020s. https://assets.publishing.service.gov.uk/government/uploads/system/uploads/attachment_data/file/819766 /advancing-our-health-prevention-in-the-2020s-accessible.pdf2019. Accessed 13 August 2019.

4. OECD. The Heavy Burden of Obesity: The Economics of Prevention. OECD Publishing; 2019. https://doi.org/10.1787/67450d67-en. Accessed 14 October 2019.

5. The NHS Long Term Plan. https://www.longtermplan.nhs.uk/wp-content/uploads/2019/01/nhs-long-termplan-june-2019.pdf: NHS; 2019. Accessed 21 August 2019. 
6. Giles L, Robinson M. Monitoring and Evaluating Scotland's Alcohol Strategy (MESAS). http://www.healthscotland.scot/publications/mesas-monitoring-report-2019: NHS Scotland; 2019.

7. Adult drinking habits in Great Britain: 2017.

https://www.ons.gov.uk/peoplepopulationandcommunity/healthandsocialcare/drugusealcoholandsmoking /bulletins/opinionsandlifestylesurveyadultdrinkinghabitsingreatbritain/2017: Office for National Statistics; 2018. Accessed 5 September 2019.

8. Roberts E, Morse R, Epstein S, Hotopf M, Leon D, Drummond C. The prevalence of wholly attributable alcohol conditions in the United Kingdom hospital system: a systematic review, meta-analysis and metaregression. Addiction (Abingdon, England). 2019.

9. Saunders JB, Walters JR, Davies AP, Paton A. A 20-year prospective study of cirrhosis. Br Med J (Clin Res Ed). 1981;282(6260):263-6.

10. National Institute for Health and Care Excellence. Cirrhosis in over 16s: Assessment and management https://www.nice.org.uk/guidance/ng50/evidence/full-guideline-pdf-25465375812016. Accessed 27 August 2019.

11. El-Gohary M, Moore M, Roderick P, Watkins E, Dash J, Reinson T, et al. Local care and treatment of liver disease (LOCATE) - A cluster-randomized feasibility study to discover, assess and manage early liver disease in primary care. PLoS One. 2018;13(12):e0208798.

12. Innovation Fund Open to Help Children of Dependent Drinkers [press release]. https://www.gov.uk/government/news/innovation-fund-open-to-help-children-of-dependent-drinkers, 22 May 2018. Accessed 15 August 2019.

13. Moriarty KJ. Alcohol Care Teams: where are we now? Frontline Gastroenterology. Published online: 14 August 2019. Doi:10.1136/flgastro-2019-101241 Accessed 5 September 2019.

14. Ward D, Murch N, Agarwal G, Bell D. A multi-centre survey of inpatient pharmacological management strategies for alcohol withdrawal. QJM. 2009;102(11):773-80.

15. Williams R, Alexander G, Aspinall R, Bosanquet J, Camps-Walsh G, Cramp M, et al. New metrics for the Lancet Standing Commission on Liver Disease in the UK. Lancet (London, England). 2017;389(10083):2053-80.

16. Drummond C, Wolstenholme A, Blackwood R, Kimergard A. Asssertive Outreach for high-need, highcost alcohol-related frequent NHS hospital attenders: the value-based case for investment. National Institute for Health Research Collaboration For Leadership in Applied Health Research and Care South London; 2019. http://www.clahrc-southlondon.nihr.ac.uk/files/Assertive\%20outreach_May_2019.pdf Accessed 20 August 2019.

17. Drummond C, Wolstenholme A, Blackwood R. Social deprivation and alcohol-related hospital admissions: study of routine hospital admissions data. Alcoholism: Clinical and Experimental Research. 2016;40(49A).

18. Rhodes D. Drug and alcohol services cut by $£ 162 \mathrm{~m}$ as deaths increase2018 20 August 2019. Available from: https://www.bbc.co.uk/news/uk-england-44039996. Accessed 20 August 2019.

19. Alcohol and drug misuse and treatment statistics. https://www.gov.uk/government/collections/alcoholand-drug-misuse-and-treatment-statistics: Public Health England; 2019. Accessed 5 September 2019.

20. Williams R, Alexander G, Aspinall R, Batterham R, Bhala N, Bosanquet N, et al. Gathering momentum for the way ahead: fifth report of the Lancet Standing Commission on Liver Disease in the UK. Lancet (London, England). 2018;392(10162):2398-412.

21. Drummond C. Cuts to addiction services are a false economy. BMJ. 2017;357:j2704.

22. Public Health England. Funding awarded to 23 projects to help those affected by alcohol. https://www.gov.uk/government/news/funding-awarded-to-23-projects-to-help-those-affected-byalcohol; 2019. Accessed 30 August 2019

23. NHS Digital. Statistics on Alcohol, England 2019 [PAS]. https://digital.nhs.uk/data-andinformation/publications/statistical/statistics-on-alcohol/20192019. Accessed 30 August 2019.

24. Beynon C, Bayliss D, Mason J, Sweeney K, Perkins C, Henn C. Alcohol-related harm to others in England: a cross-sectional analysis of national survey data. BMJ Open. 2019;9(5):e021046.

25. Burton R, Henn C, Lavoie D, O'Connor R, Perkins C, Sweeney K, et al. A rapid evidence review of the effectiveness and cost-effectiveness of alcohol control policies: an English perspective. Lancet (London, England). 2017;389(10078):1558-80.

26. Angus C, Holmes J, Pryce R, Meier P, Brennan A. Alcohol and Cancer Trends: Intervention studies. https://www.cancerresearchuk.org/sites/default/files/alcohol_and_cancer_trends_report_final_cruk.pdf: University of Sheffield and Cancer Research UK; 2016. Accessed 5 September 2019

27. Alcohol Health Alliance. How We Drink, What We Think: Public Views on Alcohol and Alcohol Policies in the UK. http://12coez15v41j2cf7acjzaodh.wpengine.netdna-cdn.com/wp-content/uploads/2018/11/AHA_Howwe-drink-what-we-think_2018_FINAL.pdf: Alcohol Health Alliance; 2018. Accessed 30 July 2019. 
28. Global Action Plan for the Prevention and Control of Noncommunicable Diseases 2013-2020. https://apps.who.int/iris/bitstream/handle/10665/94384/9789241506236_eng.pdf;jsessionid=7006482C35 7DC067DC2A2A6B607A7DEB?sequence=1: World Health Organization; 2013. Accessed 15 August 2019.

29. HM Government. Alcohol: Minimum Unit Pricing, Oral Question Hansard [Available from: https://hansard.parliament.uk/Commons/2018-05-08/debates/54040204-9E54-4E2D-B9B0-

21A9D4A24A2D/AlcoholMinimumUnitPricing?highlight=alcohol\%20strategy\#contribution-59F07EFEEB1D-431D-B883-46AB6E367E30. Accessed 30 August 2019.

30. Hammond P. Budget 2018: Philip Hammond's speech. https://www.gov.uk/government/speeches/budget2018-philip-hammonds-speech2018. Accessed 5 September 2019.

31. Alcohol, Health, Alliance. What Would You Choose? http://ahauk.org/duty-2019/; 2019. Accessed 15 August 2019.

32. Angus C, Ally A. Modelling the potential impact of duty policies using the Sheffield Alcohol Policy Model Version 3. https://www.sheffield.ac.uk/polopoly_fs/1.661443!/file/finaldurymodellingrpt.pdf: School of Health and Related Research, University of Sheffield; 2015. Accessed 5 September 2019.

33. Alcoholic Drink Voluntary Labelling Update.

https://webarchive.nationalarchives.gov.uk/20171207200436/https:/www.food.gov.uk/sites/default/files/ enf-e-17-055.pdf: Food Standards Agency; 2017. Accessed 30 July 2019.

34. BBC. Latest health guidance missing from alcohol labels 2019 [updated 30 July 2019]. Available from: https://www.bbc.co.uk/news/av/uk-48576460/latest-health-guidance-missing-from-alcohol-labels. Accessed 30 August 2019.

35. The Portman Group encourages industry to include 14 unit CMO guidance on labels [press release]. http://www.portmangroup.org.uk/media/news-details/2019/08/01/the-portman-group-encouragesindustry-to-include-14-unit-cmo-guidance-on-labels, 31 July 2019. Accessed 5 September 2019.

36. Lifestyles Team. NHS Digital. Statistics on Obesity, Physical Activity and Diet, England 2019. https://digital.nhs.uk/data-and-information/publications/statistical/statistics-on-obesity-physical-activityand-diet Government Statistical Service; 2019. Accessed 30 June 2019.

37. NHS Digital. National Diabetes Prevention Programme, 2017-18 Diagnoses and Demographics. https://files.digital.nhs.uk/1B/D8C0E4/NDA_DPP_MainReport_1718_1.1.pdf; 2019. Accessed 5 September 2019.

38. NHS Digital. National Diabetes Audit Complications and Mortality 2015-2016. 2019 https://digital.nhs.uk/data-and-information/publications/statistical/national-diabetes-audit/nationaldiabetes-audit-complications-and-mortality-2015-2016. Accessed 14 October 2019.

39. NHS Diabetes Prevention Programme (NHS DPP). https://www.england.nhs.uk/diabetes/diabetesprevention/ NHS England; 2019. Accessed 14 October 2019.

40. National Paediatric Diabetes Audit and Royal College of Paediatrics and Child Health. Annual Report 2017/18. 2019. https://www.rcpch.ac.uk/resources/npda-annual-reports. Accessed 14 October 2019.

41. Haldar D, Kern B, Hodson J, Armstrong MJ, Adam R, Berlakovich G, et al. Outcomes of liver transplantation for non-alcoholic steatohepatitis: A European Liver Transplant Registry study. J Hepatol. 2019;71(2):313-22.

42. Davies, S. Time to solve childhood obesity, an independent report by the Chief Medical Officer. https://www.gov.uk/government/publications/time-to-solve-childhood-obesity-cmo-special-report. Accessed 14 October 2019.

43. Department for Health and Social Care and Department for Digital Culture, Media and Sport. Further advertising restrictions for products high in fat, salt and sugar. https://www.gov.uk/government/consultations/further-advertising-restrictions-for-products-high-in-fatsalt-and-sugar 2019. Accessed 5 September 2019.

44. Restricting promotions of food linked to childhood obesity: public asked views [press release]. 12 January 2019. https://www.gov.uk/government/news/restricting-promotions-of-food-linked-to-childhood-obesitypublic-asked-views. Accessed 30 June 2019.

45. HM, Government. Childhood Obesity: A Plan for Action. https://assets.publishing.service.gov.uk/government/uploads/system/uploads/attachment_data/file/718903 /childhood-obesity-a-plan-for-action-chapter-2.pdf2018. Accessed 5 September 2019

46. Marteau TM, White M, Rutter H, Petticrew M, Mytton OT, McGowan JG, et al. Increasing healthy life expectancy equitably in England by 5 years by 2035: could it be achieved? Lancet (London, England). 2019;393(10191):2571-3.

47. Report of the Commission on Ending Childhood Obesity. https://www.who.int/end-childhoodobesity/publications/echo-report/en/: World Health Organization; 2016. Accessed 3 September 2019. 
48. Science Group of the European Alcohol Health Forum. Does Marketing Communication Impact on the Volume and Patterns of Consumption of Alcoholic Beverages, Especially by Young People? - A Review of Longitudinal Studies.

https://ec.europa.eu/health/ph_determinants/life_style/alcohol/Forum/docs/science_o01_en.pdf: DG SANCO, European Commission, European Alcohol and Health Forum; 2009. Accessed 3 September 2019.

49. Nagler RH, Viswanath K. Implementation and research priorities for FCTC Articles 13 and 16: tobacco advertising, promotion, and sponsorship and sales to and by minors. Nicotine Tob Res. 2013;15(4):83246.

50. Marketing of Food and Non-alcoholic Beverages to Children. 2010. https://www.who.int/dietphysicalactivity/publications/recsmarketing/en/: World Health Organization. Accessed 3 September 2019

51. Children and parents: media use and attitudes report. Ofcom; 2017 (https://www.ofcom.org.uk/researchand-data/media-literacy-research/childrens/children-parents-2017). Acccessed 3 September 2019.

52. Critchlow N, Angus K, Stead M, Newberry Le Vay J, Whiteside E, Clark M, et al. Digital Feast: Navigating a digital marketing mix, and the impact on children and young people's dietary attitudes and behaviours. https://www.cancerresearchuk.org/sites/default/files/cancer-stats/digital_feast_june_2019_-

full_report/digital_feast_june_2019_-_full_report.pdf; 2019. Accessed 29 August 2019.

53. Select Committee on Communications. 1st Report of Session 2017-19: UK Advertising in a Digital Age. In: Lords Ho, editor. https://publications.parliament.uk/pa/ld201719/ldselect/ldcomuni/116/116.pdf2018. Accessed 27 August 2019.

54. World Health Organization. Monitoring and Restricting Digital Marketing of Unhealthy Products to Children and Adolescents http://www.euro.who.int/en/health-topics/disease-prevention/nutrition/publications/2019/monitoringand-restricting-digital-marketing-of-unhealthy-products-to-children-and-adolescents-2019;2019.

Accessed 5 September 2019.

55. Brown KF, Rumgay H, Dunlop C, Ryan M, Quartly F, Cox A, et al. The fraction of cancer attributable to modifiable risk factors in England, Wales, Scotland, Northern Ireland, and the United Kingdom in 2015. Br J Cancer. 2018;118(8):1130-41.

56. Lauby-Secretan B, Scoccianti C, Loomis D, Grosse Y, Bianchini F, Straif K, et al. Body Fatness and Cancer. Viewpoint of the IARC Working Group. N Engl J Med. 2016;375(8):794-8.

57. International Agency for Research on Cancer. List of Classifications by Cancer Sites with Sufficient or Limited Evidence in Humans https://monographs.iarc.fr/agents-classified-by-the-iarc/; 2019. Accessed 30 August 2019.

58. Marrero JA, Fontana RJ, Fu S, Conjeevaram HS, Su GL, Lok AS. Alcohol, tobacco and obesity are synergistic risk factors for hepatocellular carcinoma. J Hepatol. 2005;42(2):218-24.

59. Loomba R, Yang HI, Su J, Brenner D, Barrett-Connor E, Iloeje U, et al. Synergism between obesity and alcohol in increasing the risk of hepatocellular carcinoma: a prospective cohort study. Am J Epidemiol. 2013;177(4):333-42.

60. Mahase E. Prevention Green Paper Lacks Ambition, Say Critics. BMJ. 2019;366:14829.

61. Mason R. Boris Johnson ushers in radical new era of special advisers: The Guardian; 2019 [updated 201908-05. Available from: http://www.theguardian.com/politics/2019/aug/05/boris-johnson-ushers-inradical-new-era-of-special-advisers. Accessed 5 September 2019.

62. Maani Hessari N, Petticrew M. What does the alcohol industry mean by 'Responsible drinking'? A comparative analysis. Journal of Public Health. 2017;40(1):90-7.

63. McCambridge J, Kypri K, Miller P, Hawkins B, Hastings G. Be aware of Drinkaware. Addiction (Abingdon, England). 2014;109(4):519-24.

64. Martin A, Saunders CL, Harte E, Griffin SJ, MacLure C, Mant J, et al. Delivery and impact of the NHS Health Check in the first 8 years: a systematic review. The British journal of general practice : the journal of the Royal College of General Practitioners. 2018;68(672):e449-e59.

65. NHS England. PSS14 Networked Delivery of Cirrhosis Care Bundle PSS CQUIN Indicator. https://www.england.nhs.uk/publication/pss14-cirrhosis-care-bundle-pss-cquin-indicator/2019. Accessed 21 August 2019.

66. NHS England. Specialised Services Quality Dashboards - Internal medicine metric definitions for 2018/19. https://www.england.nhs.uk/publication/specialised-services-quality-dashboards-internalmedicine-metric-definitions-for-2018-19/2019. Accessed 21 August 2019.

67. Tapper EB, Finkelstein D, Mittleman MA, Piatkowski G, Chang M, Lai M. A Quality Improvement Initiative Reduces 30-Day Rate of Readmission for Patients With Cirrhosis. Clin Gastroenterol Hepatol. 2016;14(5):753-9. 
68. Vilstrup H, Amodio P, Bajaj J, Cordoba J, Ferenci P, Mullen KD, et al. Hepatic encephalopathy in chronic liver disease: 2014 Practice Guideline by the American Association for the Study of Liver Diseases and the European Association for the Study of the Liver. Hepatology. 2014;60(2):715-35.

69. Montagnese S, Amato E, Schiff S, Facchini S, Angeli P, Gatta A, et al. A patients' and caregivers' perspective on hepatic encephalopathy. Metab Brain Dis. 2012;27(4):567-72.

70. Volk ML, Fisher N, Fontana RJ. Patient knowledge about disease self-management in cirrhosis. Am J Gastroenterol. 2013;108(3):302-5.

71. Hudson B, Round J, Georgeson B, Pring A, Forbes K, McCune CA, et al. Cirrhosis with ascites in the last year of life: a nationwide analysis of factors shaping costs, health-care use, and place of death in England. Lancet Gastroenterol Hepatol. 2018;3(2):95-103.

72. NHS Blood \& Transplant. Annual Report on Liver Transplantation: Report for 2018/2019. https://nhsbtdbe.blob.core.windows.net/umbraco-assets-corp/16782/nhsbt-liver-transplantation-annualreport-2018-19.pdf: NHS Blood \& Transplant. Accessed 22 August 2019.

73. Royal College of General Practitioners and British Liver Trust. Liver Disease Toolkit. https://www.rcgp.org.uk/clinical-and-research/resources/toolkits/liver-disease-toolkit.aspx2019. Accessed 21 August 2019.

74. Newsome PN, Cramb R, Davison SM, Dillon JF, Foulerton M, Godfrey EM, et al. Guidelines on the management of abnormal liver blood tests. Gut. 2018;67(1):6-19.

75. Dillon J, Miller M, Robinson E et al. Intelligent Liver Function Testing (iLFT): A trial of automated diagnosis and staging of liver disease in Primary Care. 2019. J Hepatol. 2019 Oct;71(4):699-706. doi: 10.1016/j.jhep.2019.05.033. Epub 2019 Jun 19.

76. Chalmers J, Wilkes E, Harris R et al. Development and implementation of a commissioned pathway for the identification and stratification of liver disease in the community. Frontline Gastroentreology. 2019; https://fg.bmj.com/content/early/2019/06/26/flgastro-2019-101177. Accessed 27 August 2019.

77. Hart CL, Morrison DS, Batty GD, Mitchell RJ, Davey Smith G. Effect of body mass index and alcohol consumption on liver disease: analysis of data from two prospective cohort studies. BMJ. 2010;340:c1240.

78. Rodijk LH, den Heijer AE, Hulscher JBF, Verkade HJ, de Kleine RHJ, Bruggink JLM. Neurodevelopmental Outcomes in Children With Liver Diseases: a Systematic Review. J Pediatr Gastroenterol Nutr. 2018;67(2):157-68.

79. Afshar S, Porter M, Barton B, Stormon M. Intellectual and academic outcomes after pediatric liver transplantation: Relationship with transplant-related factors. Am J Transplant. 2018;18(9):2229-37.

80. Talcott JB, Beath SV, Patel T, Griffiths G, Kelly DA. Long-term Effects of Cholestatic Liver Disease in Childhood on Neuropsychological Outcomes and Neurochemistry. J Pediatr Gastroenterol Nutr. 2019;69(2):145-51.

81. Parmar A, Vandriel SM, Ng VL. Health-related quality of life after pediatric liver transplantation: A systematic review. Liver Transpl. 2017;23(3):361-74.

82. Hames A, Matcham F, Joshi D, Heneghan MA, Dhawan A, Heaton N, et al. Liver transplantation and adolescence: The role of mental health. Liver Transpl. 2016;22(11):1544-53.

83. Ferrier A. Alcohol Deaths. https://www.nrscotland.gov.uk/statistics-and-data/statistics/statistics-bytheme/vital-events/deaths/alcohol-deaths: National Records of Scotland; 2019. Accessed 29 July 2019.

84. Zhao J, Stockwell T, Martin G, Macdonald S, Vallance K, Treno A, et al. The relationship between minimum alcohol prices, outlet densities and alcohol-attributable deaths in British Columbia, 2002-09. Addiction (Abingdon, England). 2013;108(6):1059-69.

85. Houses of the Oireachtas, Ireland. Public Health (Alcohol) Act 2018 (Act 24 of 2018) Public Health (Alcohol) Bill 2015 (Bill 120 of 2015). https://www.oireachtas.ie/en/bills/bill/2015/120/2018. Accessed 21 August 2019.

86. World Health Organization. Alcohol policy impact case study. The effects of alcohol control measures on mortality and life expectancy in the Russian Federation. WHO Copenhagen Regional Office for Europe; 2019. Contract No.: 978928905437 9. Accessed 16 October 2019.

\section{Contributors:}

RW was responsible for planning and providing content for the Executive Summary, Introduction and Conclusion, and writing, editing and overall direction of the paper. ND was responsible for coordinating content and editing. GA contributed content to the section on hospital workforce planning. MA, GJA, MEC, JF and GF contributed to the section on a masterplan for hospital services. RA contributed to the section on post-discharge care. $A B, A D$, DK and MS contributed to the section on paediatric liver care. KB and JV contributed to the section on obesity 
and common cancers. RBa, PN and HR contributed to the section on obesity. CD, KM and AMc contributed to the sections on addiction treatment and alcohol care teams. JG contributed to the section on the data from the ComRes poll. HJ, JM and MMa contributed to the section on primary care. IA, IG, MMk, KS, NS, HR and JV contributed to the sections on Government policy initiatives. JD, AMg, PR and AY contributed to the section on the devolved nations. $\mathrm{RBu}, \mathrm{CH}$ and NS contributed to the section on digital marketing. DT contributed to the section on liver transplantation. JW and SR contributed to the section on disease burden.

\section{Acknowledgements:}

We thank all those who attended meetings of the working groups of the Commission, including Charles Alessi (tbc); Lawrence Atkins (Incisive Health); Dr Neeraj Bhala (Queen Elizabeth Hospital Birmingham and University of Birmingham); Romain Baujard (Echosens); Graham Boal, QC; Professor Nick Bosanquet (Imperial College London); Adrian Chiles; Professor John Dillon (Medical Research Institute, University of Dundee); Kevin Fenton (Public Health England); Neil Guha (University of Nottingham); (Mark Hudson (Freeman Hospital, Newcastle); Dr Hilary Jones; Camille Manceau (Echosens); Professor Alan Maryon-Davies; Neil McDougall (Belfast Health and Social Care Trust, Northern Ireland); John McKeown; Professor John O'Grady (King's College Hospital NHS Trust); Robin Poole (Public Health England), Thomas Stephens (Incisive Health); John Wass (Dept of Endocrinology, Churchill Hospital, Oxford); Indra van Mourik (Birmingham Women's and Children's NHS Trust) and Suzanne Davison (Children's Liver Unit, Leeds Children's Hospital). We thank Norgine for their unrestricted grant to the Foundation for Liver Research, which has enabled the Commission to work with Incisive Health in bringing the work of the Commission to the attention of UK Parliament. PN was supported by the National Institute of Health Research (NIHR) Birmingham Biomedical Research Centre (BRC). 